\title{
Multidisciplinary management of juvenile nasopharyngeal angiofibroma
}

\author{
Walid Abouzeid ${ }^{1 *}\left(\mathbb{D}\right.$, Ahmed Sultan ${ }^{2}$ and Mohamed Shadad ${ }^{3}$
}

\begin{abstract}
Background: Juvenile nasopharyngeal angiofibroma (JNA) is a rare benign, but the locally aggressive, vascular tumor that occurs almost exclusively in young men. Although this tumor accounts for only about $0.5 \%$ of head and neck tumors, it is by far the most common benign nasopharyngeal neoplasm. It is presented typically with epistaxis, obstructive symptoms, and chronic otomastoiditis. The examination of this tumor reveals pale reddish-blue mass. The tumor is seen on imaging as vividly augmenting soft-tissue mass centered on the sphenopalatine foramen. The treatment of choice is usually surgical resection; either open or endoscopic. Pre-operative embolization is usually done to help with hemostasis. We aim to address the efficiency and the safety of endovascular modality in JNA.
\end{abstract}

Methods: In the period between January 2012 to December 2017, 20 male patients with age ranging from 6 to 20 years were referred to the Endovascular Unit, at Departments of Neurosurgery in Sohag, Alexandria, and Tanta University Hospitals with JNF. Preoperative trans-arterial embolization was done, followed by endoscopic surgical resection by our ENT surgeons. All patients were subjected to clinical and radiological Imaging evaluation pre embolization, post embolization, and post endoscopic resection. All patients had clinical and radiological follow-ups for at least 1 year.

Results: 20 male patients with JNA underwent preoperative super-selective trans-arterial embolization. The average age at presentation was 13 years. All patients underwent successful embolization with total obliteration of vascular blush of the tumor in 15 patients, and near-total obliteration of blush in 5 patients. The dramatic effect of preoperative embolization was observed on limiting intraoperative blood loss (average $200 \mathrm{ml}$ ) and decreasing the time of surgery (average $2.5 \mathrm{~h}$ ). There was no permanent morbidity or mortality related to either embolization or endoscopic resection in all patients.

Conclusions: Trans-arterial embolization is strongly recommended in patients with JNA, it offers a good assist to the surgeon, reduces blood loss, decreases the amount of transfusion, improves the degree of resection, reduces operative time, and decreases the incidence of recurrence.

Keywords: JNA, Endovascular embolization, PVA, Endoscopic resection

\section{Introduction}

Juvenile nasopharyngeal angiofibroma (JNA) is a quite rare benign tumor in children; that accounts for around $0.05 \%$ of all head and neck tumors [1]. JNA is nearly and

\footnotetext{
*Correspondence: walidneuro8@yahoo.com

${ }^{1}$ Department of Neurosurgery, School of Medicine, Sohag University, Naser City, Sohag 82524, Egypt

Full list of author information is available at the end of the article
}

exclusively a disease of males of adolescent age, but the age range is very wide actually, it is from 7 to 29 years [2].

The disease is typically presented initially with recurrent unilateral epistaxis, nasal obstruction and/or nasopharyngeal mass. Despite of being benign, it may be aggressive and erode the surrounding bone and soft tissues, as it evolves from its usual site in the lateral nasopharynx in the vicinity of the superior border of the sphenopalatine foramen [3]. 
Histopathologically, JNA is composed of randomly arranged vascular channels surrounded by dense fibroblastic stroma, with myofibroblasts composing the main cell [2]. The bleeding tendency of JNA is because the small blood vessels in the center of the lesion tend to lack muscular elastic lamina, predisposing these vessels to uncontrolled bleeding [3].

Diagnosis of JNA is done mainly by CT or MRI. CT can reveal the detailed bony involvement of the tumor. However, the definitive diagnosis is established by MRI imaging. The optimal method, to identify the extent of intracranial extension of JNA, is based on T1 weighted imaging (T1WI) with gadolinium contrast, using fat suppression. An MRA can add the delineation of the arterial supply to JNA which is very important for pre-embolization planning. Owing to the highly vascular nature of JNA, a biopsy is contraindicated [4]. Besides, attention must be paid to the surrounding vascular structures during resection for the fear of potentially fatal bleeding from this highly vascular area; especially the internal carotid artery, as well as any arterial supply from the contralateral external carotid artery [2].

Surgical resection is still the definite treatment for JNA. However, pre-operative angioembolization is increasingly recommended to limit the risk of uncontrolled intraoperative bleeding. Other treatment lines, including radiation, cryotherapy, electrocoagulation, or hormonal therapy, have been proved to be less effective with increased incidence of recurrence and side effects [5].

\section{Methods}

In the period between January 2012 and December 2017, 20 male patients with age ranging from 6 to 20 years were referred to Endovascular Unit, at the Departments of Neurosurgery in Sohag, Alexandria, and Tanta University Hospitals with JNA. All patients were subjected to detailed history, and took complete clinical and neurological examination, audiometric evaluation, full laboratory investigations, and finally full radiological evaluation including CT and MRI scans.

CT is especially helpful for defining bony changes. Usually, CT is seen as a lobulated non-encapsulated soft tissue mass centered on the typically widened sphenopalatine foramen. Following contrast administration, there is usually marked contrast enhancement. Massive bony destruction is not usual, but an intracranial extension could occur.

MRI is excellent for the evaluation of intra-orbital and intracranial tumor extension. The tumor is usually so intense in $\mathrm{T} 1$, heterogeneous signal in $\mathrm{T} 2$ with flow voids and prominent enhancement with gadolinium. Flow voids are present in most sequences giving characteristic salt and pepper appearance.
Extensive bony destruction is not usual with JNA, but an intracranial extension could occur. Intracranial extension may be extradural or intradural. Extension may occur from the Pterygo-palatine fossa through the pterygoid canal and foramen rotundum to the middle cranial fossa, through the pterygo-maxillary fissure to the infra-temporal fossa or through the inferior orbital fissure to the orbit. Extension to the cavernous sinus is also reported. The superior orbital fissure is the most frequent route of intracranial spread in patients with extensive involvement of the infratemporal fossa.

Under general anesthesia, standard trans-femoral approach was applied in all cases using $5 \mathrm{~F}$ and sometimes $6 \mathrm{~F}$ femoral sheath. Using $5 \mathrm{~F}$ multipurpose diagnostic catheter, angiography was done in all cases to check tumor feeders and to define dangerous anastomosis with intracranial circulation if present. Replacement with $5 \mathrm{~F}$, and sometimes $6 \mathrm{~F}$ guiding catheter, was done in all cases. The available guiding catheters in Egypt include: Chapron (Microvention, TERUMO), and Guider Softip XF (Stryker, USA). Super elective navigation of the main feeding arteries was done using flow directed microtheters, such as Marathon (Stryker, USA) or non-flow directed microcatheters, such as Echelon ${ }^{\mathrm{TM}}$ (Medtronic). The size of polyvinyl alcohol (PVA) particles (Contour particles (Boston Scientific, USA)), intended for injection, was 45-150, 150-250, and 250-355 depending on the size of the tumor vessels. Pulsed injection is implemented targeting the tumor bed until the disappearance of the tumor blush with repeated control DSA. In the end, Control DSA evaluated embolization success, after wards, started the referral to ENT department at the second morning for endoscopic excision of the tumor. Surgical excision is preferred in the first $48 \mathrm{~h}$ post embolization. Assessment of the amount of blood loss needed amount of blood transfusion; degree of resection and time of surgery was addressed. Post excision CT was done for assessment of the degree of resection. Clinical and Radiological follow-ups were made for at least 1 year in all cases.

\section{Results}

20 male patients with JNA underwent preoperative super-selective trans-arterial embolization. The average age at presentation was $13 \pm 4.1$ years (6-20 years). The presentations included epistaxis, obstructive symptoms and chronic otomastoiditis due to Eustachian tube obstruction. According to the Radkowski grading system for JNA (Table1).

[6]; 2 patients had grade IA, 6 patients had grade IB, 4 patients had grade IIA, 4 patients had grade IIB, and 2 patients had grade IIIA, and 2 patients had grade IIIB (Table 2). 
Table 1 Radkowski grading system

\begin{tabular}{ll}
\hline Stage la & Limited to nasal cavity/nasopharynx \\
Stage Ib & Extension into one or more sinuses \\
Stage Ila & Minimal extension into pterygopalatine fossa via pterygomaxillary fissure \\
Stage Illb & Fills pterygomaxillary fossa, bowing the posterior wall of the maxillary antrum anteriorly or \\
& extending into the orbit via the inferior orbital fissure without orbital erosion \\
Stage IIc & Infratemporal fossa extension without cheek or pterygoid plate involvement \\
Stage IIla & Erosion of skull base (middle cranial fossa or pterygoids) with minimal intracranial spread \\
Stage IIlb & Erosion of skull base with intracranial extension with or without cavernous sinus involvement
\end{tabular}

Table 2 Radkowski grading

\begin{tabular}{lcc}
\hline Grade & Number & Percent \\
\hline IA & 2 & 10.0 \\
IB & 6 & 30.0 \\
IIA & 4 & 20.0 \\
IIB & 4 & 20.0 \\
IIIA & 2 & 10.0 \\
IIIB & 2 & 10.0 \\
Total & 20 & 100.0 \\
\hline
\end{tabular}

Table 3 Arterial feeders

\begin{tabular}{ll}
\hline Arterial Feeder & $\begin{array}{l}\text { No. of } \\
\text { patients }\end{array}$ \\
\hline External carotid artery & 20 \\
Internal maxillary A: sphenopalatine and descending & 20 \\
palatine A & \\
Ascending pharyngeal A: pharyngeal trunk (sup. branch) & 10 \\
Facial A: ascending palatine A & 6 \\
Internal carotid artery & 5 \\
Peterous branches (vidian A) & 4 \\
Inferolateral trunk & 1 \\
\hline
\end{tabular}

Feeding arteries included most commonly internal maxillary artery through sphenopalatine and descending palatine arteries (branches of the internal maxillary artery), a superior pharyngeal artery from pharyngeal trunk (branch of ascending pharyngeal artery, ascending palatine artery (branch of the facial artery), and petrous branches from the internal carotid artery. In one case with grade IIIA; feeders were shown from both sides (Table 3).

All patients underwent successful super-selective trans-arterial embolization with total obliteration of vascular blush of the tumor in 15 patients, and near-total obliteration of blush in 5 patients. These 5 patients had supplementary feeders from the internal carotid artery or external carotid artery with dangerous anastomosis to the internal carotid artery. The embolization of these small feeders is technically difficult and carries risk for dangerous complications. ENT surgeons reported no significant bleeding in these cases with near-total embolization.

Necrosis was evaluated by absent enhancement or a decrease of contrast uptake in post embolization contrasted CT and MRI. No permanent morbidity or mortality, related to embolization techniques in our series, was shown.

Surgical reports from our ENT surgeons showed a dramatic effect of preoperative embolization on limiting the amount of intraoperative blood loss and decreasing the time of surgery. Two patients required combined endoscopic and transcranial approaches and another two patients required pure transcranial approach for complete excision of the lesions. The average intraoperative blood loss was $225 \pm 82 \mathrm{ml}$ (range $100-400 \mathrm{ml}$ ), no transfusion was needed in 14 patients $(70 \%)$, and the average operative time was $2.53 \pm 0.57 \mathrm{~h}$ (range $2-4 \mathrm{~h}$ ). No permanent morbidity or mortality, related to surgical techniques in our series, was shown other than one patient revealed CSF leak that treated medically. The mean hospital stay was $5.2 \pm 1.1$ days (4-7 days) for both embolization and surgery.

The mean follow-up period was $2.1 \pm 1.6$ years (1-4 years). Only one patient had recurrence after 1.5 years and was treated by trans-arterial embolization followed by surgical resection. Another patient had a small residual after endoscopic removal and remained stable under follow-up.

\section{Discussion}

JNA are a group of highly vascular benign tumors seen exclusively in pediatric to adolescent males, and in most cases manifested with recurrent epistaxis. They are centered on the sphenopalatine foramen and extend into the neighboring structures causing bone erosive changes [7, 8].

The current study included 20 male patients with JNA who underwent preoperative super-selective trans-arterial embolization. In addition, all of the cases studied by 

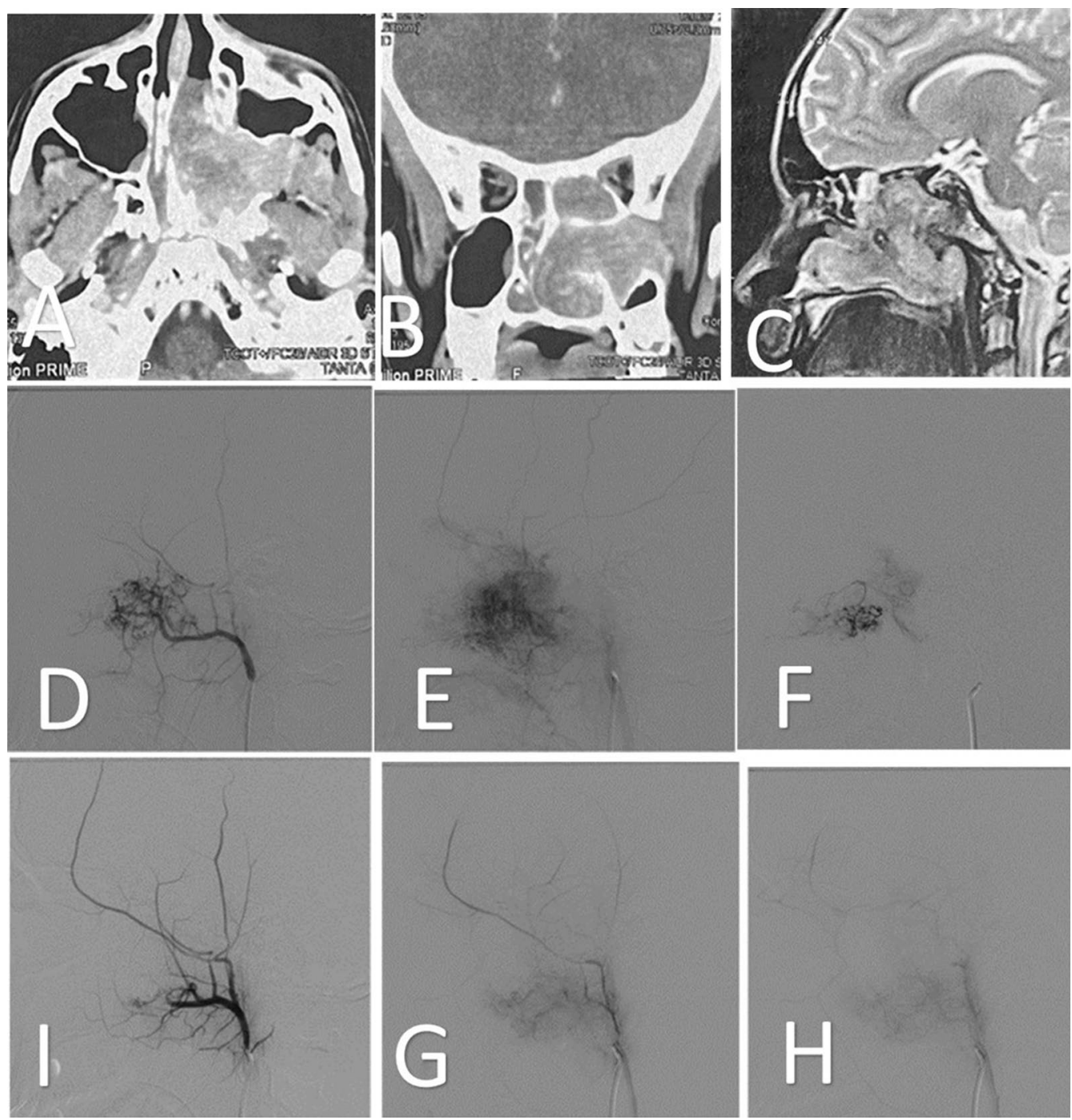

Fig. 1 A Male child, 14 years, presented with epistaxis and nasal obstruction. Nasal biobsy was tried with horrible bleeding CT and MRI showed the presence of nasopharyngeal angiofibroma. Endovascular embolization was done with successful obliteration of tumor blush followed by successful surgical excision. A, B CT PNS (axial and Coronal) shows tumor, C MRI PNS (sagittal T2) shows tumor extensions D, E Distal ECA angiogram lateral view (arterial, and capillary, phases) shows tumor feeders and blush. F Super-selective catheterization of different feeders in different tumor compartments (mainly sphenopalatine artery branches) I-H Control ECA angiogram lateral view (arterial, capillary, and venous phases) shows obliteration of tumor blush in different tumor compartments

Amran et al. [9], Lv et al. [10], Banjara et al. [11], Kasem et al. [12], Gemmete et al. [13], Punj et al. [14] and Rosenbaum-Halevi et al. [15] were males.

The mean age at presentation was $13 \pm 4.1$ years. This was similar to the age average of Rosenbaum-Halevi et al. [15] and Kasem et al. [12] studies which showed a mean age of 14.1 years in both studies, and that of Banjara et al. [11] study which had a mean age of 14.5 years. This mean age was slightly lower than that of Gemmete et al. [13], which was 15 years, and that of Lv et al. [10] and Punj et al. [14] cases, which was around 16 years. 4 out of the 5 cases studied by Amran et al. [9] had an age range from 11 to 16 years, but the fifth case was much older; 61 years. According to the Radkowski grading system for NPA; 2 patients had grade IA, 6 patients had grade IB, 6 patients had grade IIA, 4 patients had grade IIB, 2 patients had grade IIIA. This distribution was somewhat different from that of Lv et al. [10] cases, where most of the cases had grade IIIA, IIIB or IIC. In the study of Rosenbaum-Halevi et al. [15], all cases were in grade II, IIA, IIB or IIC. All of the cases of Banjara et al. [11] were either stage II or III. In the study of Gemmete et al. [13], 

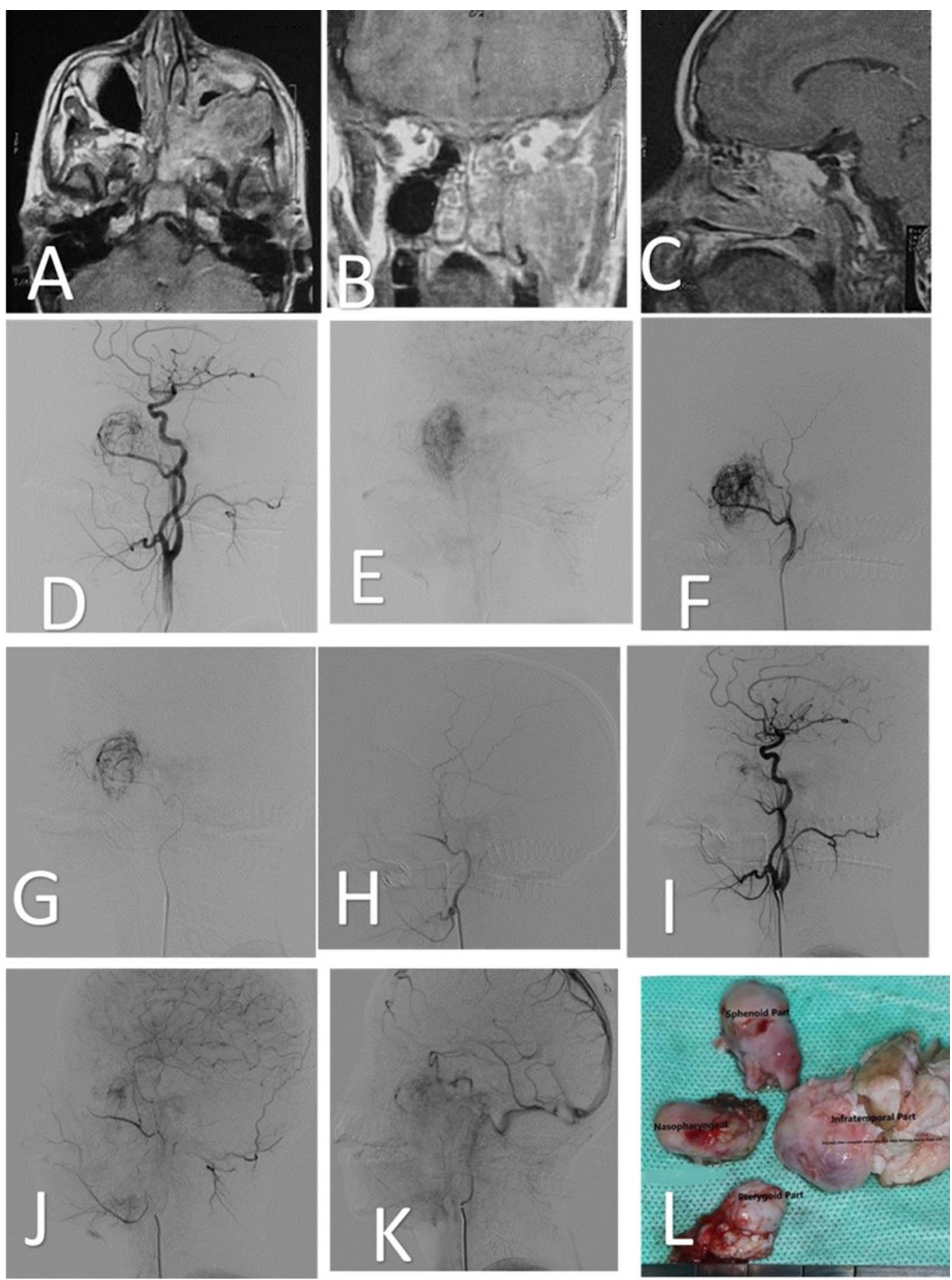

Fig. 2 A Male child, 13 years, presented with epistaxis and nasal obstruction. CT and MRI showed the presence of nasopharyngeal angiofibroma. Endovascular embolization was done with successful obliteration of tumor blush followed by successful surgical excision. A-C Enhanced MRI PNS (axial, coronal and sagittal) shows tumor extensions D, E CCA angiogram lateral view (arterial, and capillary) shows tumor feeders and blush. F, G Selective and super-selective catheterization of ECA artery (main feeder) $\mathbf{H}$ Control ECA angiogram lateral view shows obliteration of tumor blush in different tumor compartments. I-K Control CCA angiogram lateral view (arterial, capillary, and venous phases) shows obliteration of tumor blush in different tumor compartments, L Different parts of totally endoscopic removed tumor 

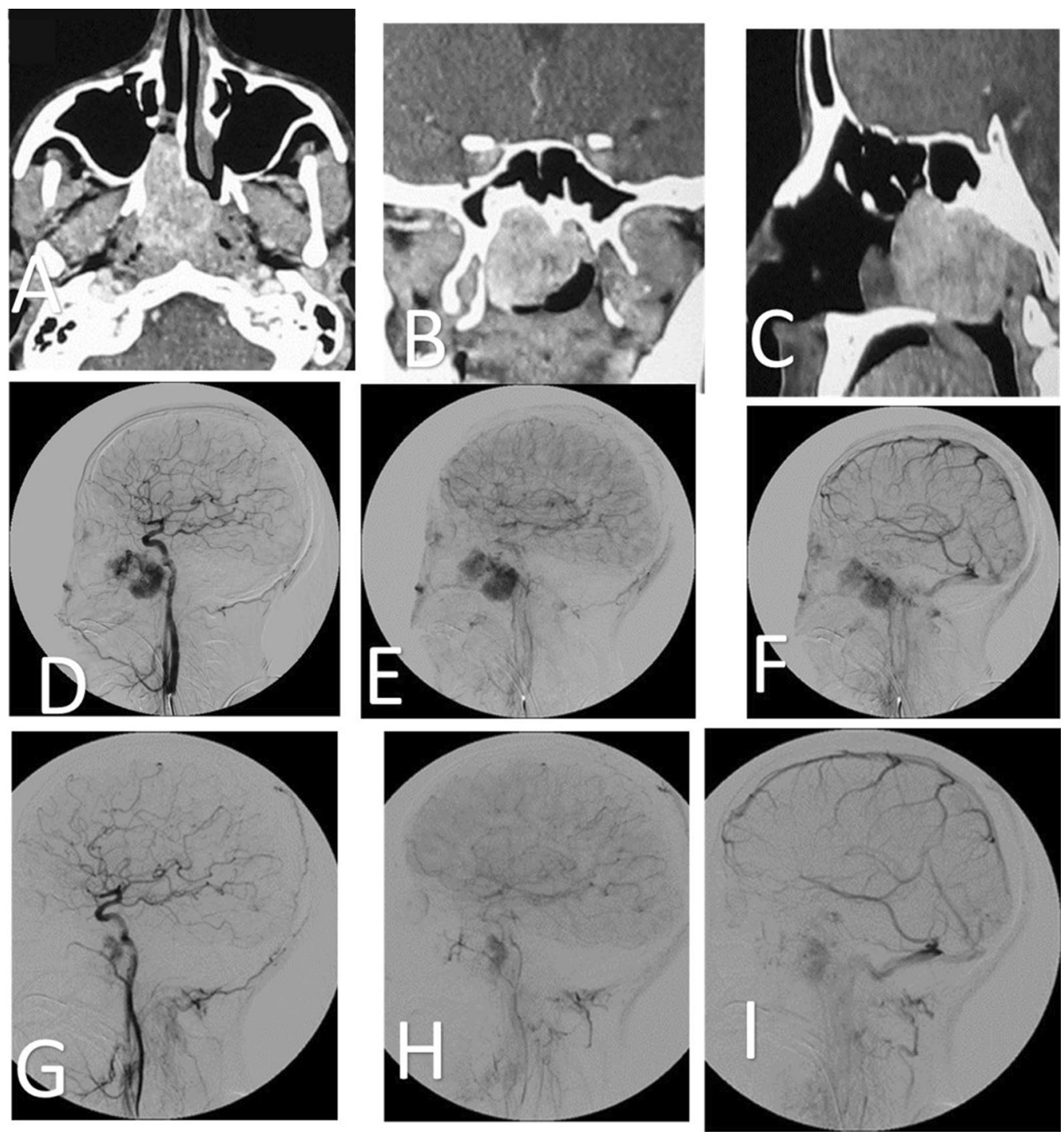

Fig 3 A Male child, 10 years, presented with epistaxis. CT showed the presence of nasopharyngeal angiofibroma. Endovascular embolization was done with successful obliteration of tumor blush followed by successful surgical excision. A-C Enhanced CT scan PNS (axial, coronal and sagittal) shows tumor extensions D-F CCA angiogram lateral view (arterial, capillary, and venous phases) shows tumor feeders and blush. G-I Control CCA angiogram lateral view (arterial, capillary, and venous phases) shows subtotal obliteration of tumor blush in different tumor compartments (except part supplied by ICA)

6 cases were grade III, with only 2 cases were grade II and one case was grade I. According to the study of Punj et al. [14], most cases belonged to stage IIC.

No permanent morbidity or mortality, related to embolization techniques in our series, was shown. This was similar to the findings reported by Amran et al. [9] and Rosenbaum-Halevi et al. [15].

The average intraoperative blood loss was $225 \pm 82 \mathrm{ml}$, and no transfusion was needed in 14 patients (70\%) in the current study. This was somewhat similar to that of Kasem et al. [12] cases, who recorded a mean blood loss of $150 \mathrm{ml}$ and Rosenbaum-Halevi et al. [15], who recorded a mean blood loss of around $330 \mathrm{ml}$. The average blood loss in the cases of Amran et al. [9] and Gemmete et al. [13] were somewhat higher than that in our cases, being around $500 \mathrm{ml}$ and $567 \mathrm{ml}$, respectively. In the study of Lv et al. [10], no case needed blood transfusion at all. However, the average blood loss in the Banjara et al. [11] study cases were much higher, being up to $900 \mathrm{ml}$ for stage II cases, and $1600 \mathrm{ml}$ for stage III cases. This was reflected in the findings that all of the Banjara et al. [11] cases needed a blood transfusion, which is 
much different from the current study cases. In addition, the mean blood loss in the study of Punj et al. [14] reached up to $1240 \mathrm{ml}$, with a very wide range, from $50 \mathrm{ml}$ to $6 \mathrm{~L}$.

The average operative time was $2.53 \pm 0.57 \mathrm{~h}$. These findings were similar to the study of Kasem et al. [12] who reported a mean operative time of around $2.5 \mathrm{~h}$. In addition, this was somewhat similar to that of Banjara et al. [11] study, with a mean operative time of around $133 \mathrm{~min}$ for stage II cases, and $167 \mathrm{~min}$ for stage III cases. The study of Punj et al. [14] revealed a mean operative time of around $165 \mathrm{~min}$. On the other hand, the average operative time in the Gemmete et al. [13] and Rosenbaum-Halevi et al. [15] studies were higher, being around 5.5 and $4.5 \mathrm{~h}$, respectively.

No permanent morbidity or mortality, related to surgical techniques in our series, was shown. This was similar to the findings of Lv et al. [10], Punj et al. [14] and Kasem et al. [12].

In this study, the mean hospital stay was $5.2 \pm 1.1$ days, which was somewhat similar to that reported by Amran et al. [9]. On the other hand, the hospital stay of the current study was much lower than that of the Banjara et al. [11] study, which reported a hospital stay of 10 days for stage II cases, and 16 days for stage III cases. In addition, our cases stayed in hospital less than Punj et al. [14] cases, who had a mean hospital stay of 8.3 days.

The mean follow-up period was $2.3 \pm 1.6$ years. Only one patient had recurrence after 1.5 years, and treated by trans-arterial embolization followed by surgical resection. In the study of Rosenbaum-Halevi et al. [15], one case $(11.1 \%)$ had recurrent after 14 months.

One patient (5\%) in the current study had a small residual after endoscopic removal and remained stable under follow-up. The study of Lv et al. [10] stated that $13.6 \%$ of their cases showed residual lesions at follow-up visits. In addition, the Rosenbaum-Halevi et al. [15] study reported one case (11.1\%) with a residual lesion.

In this study and previously reported studies, endovascular embolization carries high degree of efficacy in the management of vascular brain tumors. Direct surgery in almost all cases is aborted due to massive blood loss. Embolization is associated with minimal blood loss, minimal operative time, easier excision, and minimal hospital stay [16].

\section{Conclusions}

Trans-arterial embolization is strongly recommended in patients with JNA, and offers a good assist to the surgeon, reduces blood loss, decreases the amount of transfusion, improves the degree of resection, reduces operative time and decreases the incidence of recurrence (Figs. 1, 2, and $3)$.

\section{Abbreviations}

JNA: Juvenile nasopharyngeal angiofibroma; CT: Computed Tomography; MRI: Magnetic resonance imaging; T1WI:T1 weighted image; MRA: Magnetic resonance angiography; 5F: Five french; PVA: Poly venyl alcohol; DSA: Digital subtraction angiography; ENT: Ear, nose, and throat; PNS: Para nasal sinuses.

\section{Acknowledgements}

Not applicable.

\section{Authors' contributions}

WA: conceptualization, data curation, formal analysis, project administration, software, writing —original draft, methodology, intervention, supervision, resources, and final review and editing. AS: data curation, investigation, and supervision. MS: validation, visualization, and writing — review and editing. All authors read and approved the final manuscript.

\section{Funding}

This research did not receive any specific grant from funding agencies in the public, commercial, or non-profit sectors.

\section{Availability of data and materials}

All the aforementioned data and results of the statistical analysis are available with the authors and ready to be shared with approved personnel upon request.

\section{Declarations}

\section{Ethics approval and consent to participate}

All patients were informed about the benefits and the risks of the intended procedure; an informed written consent was signed at least $24 \mathrm{~h}$ before the operation. Ethical approval of sohag faculty of medicine was addressed on 08/09/2021 under IBR registration number: soh-med-21-09-49.

\section{Consent for publication}

Not applicable.

\section{Competing interests}

The authors declare that they have no competing interests.

\section{Author details}

${ }^{1}$ Department of Neurosurgery, School of Medicine, Sohag University, Naser City, Sohag 82524, Egypt. ${ }^{2}$ Department of Neurosurgery, Alexandria University, Alexandria, Egypt. ${ }^{3}$ Department of Neurosurgery, Tanta University, Tanta, Egypt.

Received: 1 September 2021 Accepted: 9 November 2021

Published online: 11 December 2021

\section{References}

1. Boghani Z, Husain Q, Kanumuri VV, Khan MN, Sangvhi S, Liu JK, et al. Juvenile Nasopharyngeal Angiofibroma: a Systematic review and comparison of endoscopic, endoscopic-assisted, and open resection in 1047 cases. Laryngoscope. 2013;123(4):859-69.

2. Parikh V, Hennemeyer C. Microspheres embolization of juvenile nasopharyngeal angiofibroma in an adult. Int J Surg Case Rep. 2014;5(12):1203-6.

3. Moorthy PN, Ranganatha Reddy B, Qaiyum HA, Madhira S, Kolloju S. Management of juvenile nasopharyngeal angiofibroma: a five-year retrospective study. Indian J Otolaryngol Head Neck Surg. 2010;62(4):390-4.

4. Mishra S, Praveena NM, Panigrahi RG, Gupta YM. Imaging in the diagnosis of juvenile nasopharyngeal angiofibroma. J Clin Imaging Sci. 2013;3(Suppl 1):1 
5. Hira A, Chao K. Direct endoscopic intratumoral injection of Onyx for the preoperative embolization of a recurrent juvenile nasal angiofibroma. Interv Neuroradiol. 2011;17(4):477-81.

6. Radkowski D, Mcgill T, Healy GB, et al. Angiofibroma: changes in staging and treatment. Arch Otolaryngol Head Neck Surg. 1996;122:122-9.

7. Midilli R, Karci B, Akyildiz S. Juvenile nasopharyngeal angiofibroma: analysis of 42 cases and important aspects of endoscopic approach. Int J Pediatr Otorhinolaryngol. 2009;73(3):401-8.

8. Bleier BS, Kennedy DW, Palmer JN, Chiu AG, Bloom JD, O'Malley BW Jr. Current management of juvenile nasopharyngeal angiofibroma: a tertiary center experience 1999-2007. Am J Rhinol Allergy. 2009;23(3):328-30.

9. Amran MY, Bahar A. Case series of pre-operative endovascular embolization of nasopharyngeal angiofibroma using polyvinyl alcohol foam particle: a single centre experience. Open Access Maced J Med Sci. 2019;7(15):2502.

10. Lv MM, Fan XD, Su LX, Chen D. Preoperative direct puncture embolization of advanced juvenile nasopharyngeal angiofibroma in combination with transarterial embolization: an analysis of 22 consecutive patients. Cardiovasc Intervent Radiol. 2013;36(1):111-7.

11. Banjara H, Sahu CD, Arya A. A study on role of Preoperative embolisation in surgery of Juvenile Nasopharyngeal Angiofibroma and its outcome. Int J Res Health Sci. 2015;3(2):337-44.

12. Kasem MAHO, Awad AS, Al Bosraty HADM, Kamel Al. Preoperative embolization of nasopharyngeal angiofibromas: The role of direct percutaneous injection of cyanoacrylate glue in conjunction with particulate endovascular approach. Egypt J Radiol Nucl Med. 2016;47(4):1431-41.
13. Gemmete JJ, Patel S, Pandey AS, Sullivan SE, McKean EL, Marentette LJ, et al. Preliminary experience with the percutaneous embolization of juvenile angiofibromas using only ethylene-vinyl alcohol copolymer (Onyx) for preoperative devascularization prior to surgical resection. AJNR Am J Neuroradiol. 2012;33(9):1669-75.

14. Punj J, Chopra S, Garg A, Pandey R, Darlong V, Sinha R, et al. Perioperative Management of Juvenile Nasopharyngeal Angiofibroma: A Retrospective Analysis of 56 Patients From a Single Tertiary Care Institute. AANA J. 2016;84(5):348-56.

15. Rosenbaum-Halevi D, Lopez-Rivera V, Turkmani A, Sanzgiri A, Zeineddine HA, Luong A, et al. A safer endovascular technique for pre-operative embolization of juvenile nasopharyngeal angiofibroma: avoiding the pitfalls of external carotid artery - internal carotid artery anastomoses. J Cerebrovasc Endovasc Neurosurg. 2020;22(2):97-105.

16. Sultan A, Hassan T, Aboul-Enein H, Mansour O, Ibrahim T. The value of preoperative embolization in large and giant solid cerebellar hemangioblastomas. Interv Neuroradiol. 2016;22(4):482-8. https://doi.org/10.1177/ 1591019916633244.

\section{Publisher's Note}

Springer Nature remains neutral with regard to jurisdictional claims in published maps and institutional affiliations.

\section{Submit your manuscript to a SpringerOpen ${ }^{\circ}$ journal and benefit from:}

- Convenient online submission

- Rigorous peer review

- Open access: articles freely available online

- High visibility within the field

- Retaining the copyright to your article

Submit your next manuscript at $\boldsymbol{\nabla}$ springeropen.com 